\title{
Yielding and Growing of Adipose Stem Cell Harvested from the Superficial and Deep Abdominal Subcutaneous Fat: A Case
}

Daegu Son*

Department of Plastic and Reconstructive Surgery, Keimyung University school of Medicine, Daegu, Korea

\begin{abstract}
A 60 year old woman was enrolled in our study. She was $151 \mathrm{~cm}$ tall, weighed $73 \mathrm{~kg}$ and had high body mass index $\left(33.19 \mathrm{~kg} / \mathrm{m}^{2}\right)$. Adipose tissue specimens were taken from her abdomen by surgical excision. ASCs were isolated in primary culture and cell counts were performed by using an automated cell counter (LUNA ${ }^{\mathrm{TM}}$ ). And $5 \times$ $10^{3}$ ASCs were seeded into DMEM tissue culture flasks and were cultured for 16 days $(n=3)$. Lastly, self-renewal capacity was demonstrated by colony-forming unit fibroblast (CFUF) assays $(n=3)$.
\end{abstract}

Keywords: Adipose stem cell; Subcutaneous fat

\section{Case Report}

Subcutaneous fat is a valuable source of adipose-derived stem cells (ASCs). There are two anatomically distinct compartments of subcutaneous fat tissue in human: superficial adipose tissue (SAT) and deep adipose tissue (DAT). Abdominal subcutaneous fat is also separated by scarpa's fascia into two layers, which are SAT and DAT. The difference between SAT and DAT had been studied in anatomy $[1,2]$, structure and function [3], insulin resistance [4], molecular and morphologic character [5] and metabolic markers [6]. Taranto et al. recently demonstrated that SAT contained a higher stromal tissue compound and features increased stem properties [7].

We have observed yielding and growing of ASCs derived from SAT and DAT. The entire protocol was approved by the institutional review board (No. 12-146) at the Dongsan Presbyterian Hospital (Daegu, Republic of Korea). A 60 year old woman was enrolled in our study. She was $151 \mathrm{~cm}$ tall, weighed $73 \mathrm{~kg}$ and had high body mass index (33.19 $\mathrm{kg} / \mathrm{m}^{2}$ ) and was admitted for breast reconstruction. Adipose tissue specimens were harvested from zone IV of transverse rectus abdominis musculocutaneous (TRAM) flap and were separated into SAT and DAT by surgeon (author) at operating room. The specimens were transferred to laboratory immediately for preparation.

The purified fat was minced and washed with PBS, and digested with type I collagenase for $40 \mathrm{~min}$. Equal amount of DMEM (10\% FBS) was added to stop enzyme action. The digested tissue was filtered through a $200 \mu \mathrm{m}$ strainer. After two centrifugations ASCs were isolated in primary culture and cell counts were performed three times for every sample by using an automated cell counter (LUNA ${ }^{\mathrm{m}}$, Logos biosystems, Anyang, South Korea). And $5 \times 10^{3}$ ASCs were seeded into DMEM tissue culture flasks and were cultured for 16 days. Lastly, self-renewal capacity was demonstrated by colony-forming unit fibroblast (CFU-F) assays.

For growth curve analysis, cell counts were compared by $t$-test for individual comparisons (Figure 1).

Total cell count of ASCs derived from DAT was higher than SAT group but live cell count of ASCs derived from DAT was lower than SAT group (Table 1). Cell growth rate of DAT group was higher than SAT group and last cell count of DAT group was higher than SAT group

\begin{tabular}{|c|c|c|c|}
\hline Type & Total fat weight $\mathbf{~ g )}$ & Total cell yield/g & Live cell yield/g \\
\hline DAT & 117.0 & $1.8 \times 10^{4} \pm 9.8 \times 10^{3}$ cells & $6.3 \times 10^{3} \pm 8.8 \times 10^{2}$ cells \\
\hline SAT & 180.3 & $1.1 \times 10^{4} \pm 1.9 \times 10^{3}$ cells & $7.6 \times 10^{3} \pm 1.4 \times 10^{3}$ cells \\
\hline
\end{tabular}

Table 1: Yield of adipose derived stem cell; total cell count of ASCs derived from DAT was higher than SAT group but live cell count of ASCs derived from DAT was lower than SAT group.

(Figure 1). CFU-F assays revealed that SAT group formed fewer and smaller colonies but DAT group formed multiple and larger colonies. And optical density of DAT group was higher than SAT group. This means that self-renewal capacity of ASCs derived from DAT was better than SAT group (Figures 2 and 3). In summary, SAT contained a higher amount of ASCs but the growth rate and self-renewal capacity were lower than DAT.

Harvesting of DAT from SAT is not an easy procedure. A scarpa's fascia can be clearly demonstrated under CT and MRI but in clinical field it is almost impossible to harvest only deep abdominal fat using a suction cannula during liposuction. Even in the excised full layer of abdominal skin and subcutaneous fat the scarpa's fascia is unclear medially. Especially in lower BMI patients who have thin DAT layer, harvesting is even more difficult.

As far as we are aware, this is the first study of comparing growth rate of SAT and DAT. Our case study showed that DAT has better growth and self-renewal capacity than SAT. This result was different from Taranto et al. study [7]. Although our study has a limit as a case study, these results may provide a clue to further study about SAT and DAT.

*Corresponding author: Daegu Son, Department of Plastic and Reconstructive Surgery, Keimyung University, School of Medicine, Daegu, Korea, Tel: 82532508505; E-mail: handson@dsmc.or.kr

Received October 10, 2016; Accepted November 16, 2016; Published November 26, 2016

Citation: Son D (2016) Yielding and Growing of Adipose Stem Cell Harvested from the Superficial and Deep Abdominal Subcutaneous Fat: A Case. J Tissue Sci Eng 7: 185. doi:10.4172/2157-7552.1000185

Copyright: (๑) 2016 Son D. This is an open-access article distributed under the terms of the Creative Commons Attribution License, which permits unrestricted use, distribution, and reproduction in any medium, provided the original author and source are credited. 
Citation: Son D (2016) Yielding and Growing of Adipose Stem Cell Harvested from the Superficial and Deep Abdominal Subcutaneous Fat: A Case. $\mathrm{J}$ Tissue Sci Eng 7: 185. doi:10.4172/2157-7552.1000185

\section{Cell growth curve (total cells)}

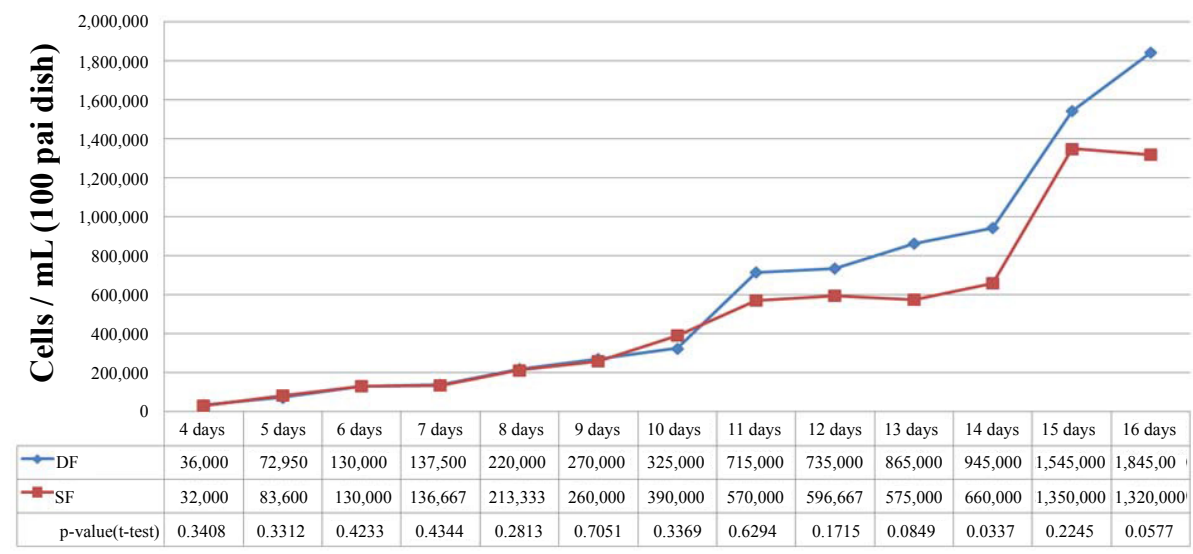

Figure 1: Cell growth curve; cell growth rate was similar until 10 days of culture, but DAT (DF) group was higher than SAT (SF) group after 11 days of culture and last cell count of DAT group was higher than SAT group.

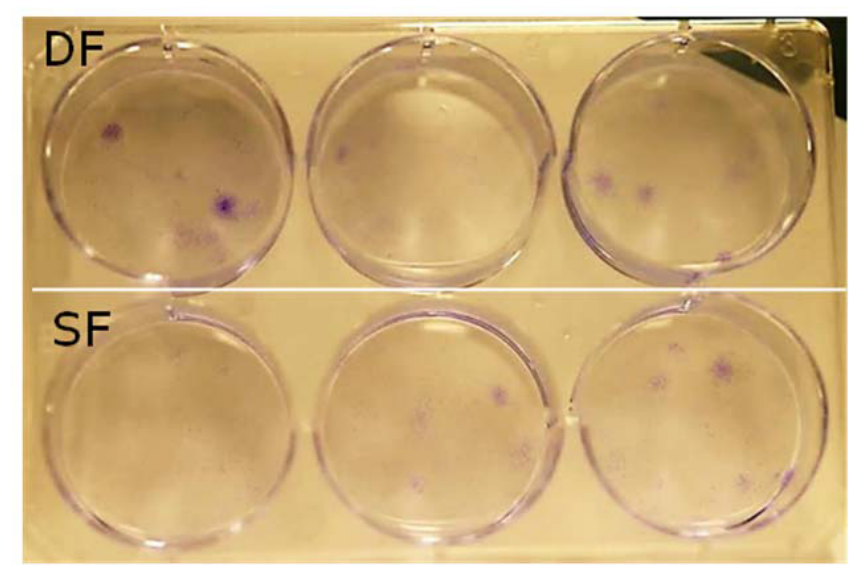

Figure 2: Colony-forming unit fibroblast (CFU-F) assays; cell colonies were stained with $1 \%$ crystal-violet in methanol at $15^{\text {th }}$ day of culture. SAT (SF) groups (lower three culture dishes) established fewer and smaller colonies but DAT (DF) groups (upper three culture dishes) established multiple and lager colonies.

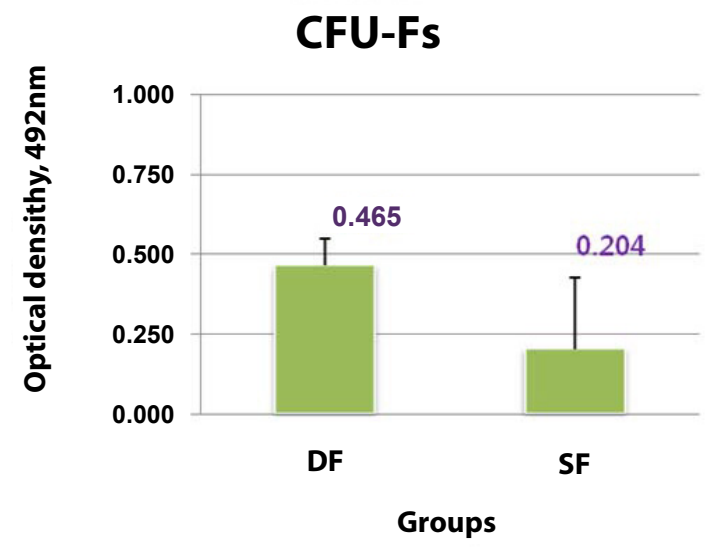

Figure 3: Optical density of Colony-forming unit fibroblast (CFU-F) under illumination at a wavelength of $492 \mathrm{~nm}$; optical density of DAT group (mean 0.465 ) was higher than SAT (SF) group (mean, 0.204). This means that selfrenewal capacity of ASCs derived from DAT (DF) was relatively two times higher than ASCs derived from SAT.

\section{References}

1. Shin D, Son D, Park M, Kim J, Han K. (2010) Characteristics of fat tissue according to the anatomical regions of the body: Computed tomographic and histological findings. J Korean Soc Plast Reconstr Surg 37: 535-546.

2. Lancerotto L, Stecco C, Macchi V, Porzionato A, Stecco A, et al. (2011) Layers of the abdominal wall: anatomical investigation of subcutaneous tissue and superficial fascia. Surg Radiol Anat 33: 835-842.

3. Marinou K, Hodson L, Vasan SK, Fielding BA, Banerjee R, Brismar K, et al. (2014) Structural and functional properties of deep abdominal subcutaneous adipose tissue explain its association with insulin resistance and cardiovascular risk in men. Diabetes Care 37: 821-829.

4. Kelley DE, Thaete FL, Troost F, Huwe T, Goodpaster BH (2000) Subdivisions of subcutaneous abdominal adipose tissue and insulin resistance. Am J Physiol Endocrinol Metab 278: E941-948.

5. Cancello R, Zulian A, Gentilini D, Maestrini S, Barba AD, et al. (2013) Molecular and morphologic characterization of superficial- and deep-subcutaneous adipose tissue subdivisions in human. Obesity 21: 2562-2570.

6. Walker GE, Marzullo P, Prodam F. Bona G, Blasio AMD (2014) Obesity modifies expression profiles of metabolic markers in superficial and deep subcutaneous abdominal adipose tissue depots. Endocrine 46: 99-106.

7. Taranto GD, Cicione C, Visconti G, Isgro M, Barba M, et al. (2015) Qualitative and quantitative differences of adipose-derived stromal cells from superficial and deep subcutaneous lipoaspirates: A matter of fat. Cytotherapy 17: 10761089. 